American Journal of Pharmaceutical Education 2019; 83 (5) Article 6706.

\title{
RESEARCH
}

\section{The Roles of Empathy, Attachment Style, and Burnout in Pharmacy Students' Academic Satisfaction}

\author{
Rute Gonçalves Silva, MS, ${ }^{a}$ Margarida Figueiredo-Braga, PhD, MD \\ ${ }^{\text {a }}$ Faculty of Medicine, University of Porto, Portugal \\ ${ }^{\mathrm{b}}$ Instituto de Inovação e Investigação em Saúde I3S, Porto, Portugal \\ Submitted August 9, 2017; accepted January 9, 2018; published June 2019.
}

Objective. To investigate empathy, burnout, and attachment style, and explore the relationships between these variables and academic satisfaction in a group of pharmacy students.

Methods. Students enrolled in the first two years $(n=200)$ and last two years $(n=210)$ of a five-year master's degree program in pharmaceutical sciences were invited to participate. The data collected included sociodemographic characteristics; responses on the Portuguese version of the Interpersonal Reactivity Index (IRI) to assess empathy levels; responses on the Maslach Burnout Inventory (MBI) to measure emotional exhaustion, depersonalization, and personal accomplishment; responses on the Adult Attachment Scale (AAS) to evaluate students' attachment style; and responses on an original academic satisfaction scale.

Results. Although students in both groups had similar levels of empathy, female students had significantly higher scores in the IRI subscales and in emotional exhaustion. Students in the last two years of the program had significantly higher depersonalization scores. The majority of students reported that they were satisfied with the quality of their academic experience, however, the satisfaction scores of students enrolled in their first two years were significantly higher. Attachment styles explained $14 \%$ of all students' depersonalization and academic satisfaction scores (11\%). Burnout explained 39\% of all students' academic dissatisfaction.

Conclusion. Although a majority of pharmacy students were satisfied with their academic life, burnout negatively influenced the academic satisfaction of some students completing the final years of their education. The type of interpersonal relationship students have influences their ability to understand patients and the quality of their learning experience. A large percentage of students indicated they had a significant level of burnout, which underscores the need to provide preventive and restorative interventions for these students.

Keywords: pharmacy students, empathy, burnout, attachment, academic satisfaction

\section{INTRODUCTION}

Numerous factors influence the emotional health of pharmacy students, and as they progress through their educational career, it is important for academic institutions to monitor indicators of mental health and academic satisfaction as it is to monitor grades. Previous studies have established the influence of health professionals' empathic ability in their global efficiency and in patients' satisfaction and cooperation. ${ }^{1-3}$ Pharmacy students' technical skills in delivering therapeutic recommendations may be negatively affected by their inability to communicate or relate to patients. In fact, to patients, the per-

Corresponding Author: Margarida Figueiredo-Braga, I3SInstituto de Inovação e Investigação em Saúde, Rua Alfredo Allen, 208, 4200-135 Porto, Portugal. Tel: +351-220-408800. E-mail: mmfb@med.up.pt ceived emotional support and understanding from health professionals is a critical determinant of the quality of the relationship established, and influences treatment engagement and health outcomes. ${ }^{2,4,5}$ Classically, the term empathy incorporates a person's aptitude for experiencing others' psychological states, ability to comprehend others' feelings, and capacity to see the world through another person's perspective. Although difficult to integrate into a curriculum and clinical practice, the teaching of patient-centered communication and empathic care needs to be developed to ensure pharmacy students will be able to communicate effectively in professional life $e^{7,8}$ and this training is being included in more and more pharmacy education programs. ${ }^{6-11}$ Appropriate and accurate therapeutic recommendations from pharmacists are far more valuable when effectively and professionally 


\section{American Journal of Pharmaceutical Education 2019; 83 (5) Article 6706.}

communicated. ${ }^{12-15}$ Furthermore, empathic statements are known to build cooperative and trusting relationships with patients, which are important to patients maintaining their adherence to pharmacists' recommendations ${ }^{12}$ and enhancing their satisfaction with the care provided. ${ }^{13} \mathrm{~A}$ health care provider demonstrating affective concern for a patient, for example, is considered a critical determinant of therapeutic effects and health outcomes in the case. ${ }^{16}$

Personal variables, such as attachment style, may contribute to individual differences in a provider's ability to understand, connect with, and care for others. ${ }^{17,18}$ Attachment, defined as the human predisposition to emotionally connect and perceive close relationships ${ }^{19}$ and intimacy, may facilitate or impede the development of empathic abilities among health professionals and students..$^{20,21}$

Classically, three attachment styles have been proposed: secure, anxious, and avoidant. Securely attached individuals can communicate and seek support from others in times of need; conversely, they also have the potential for high levels of caregiving. ${ }^{21}$ They are more able to establish close relationships and to respond to and explore patients' worries, ${ }^{22-25}$ and communicate in a flexible, patient-centered way. ${ }^{20}$ In contrast, anxious attached individuals show less comfort with closeness in relationships, ${ }^{26,27}$ and may be less able to appropriately respond to patients' emotions. ${ }^{20,22-24,28,29}$ Finally, avoidant individuals present uncertainty about themselves and others, ${ }^{20,28}$ and they may exhibit avoidance of closeness with others because of negative expectations. ${ }^{19,30}$

When these personal characteristics occur, some may contribute to emotional exhaustion and a feeling of reduced personal fulfillment. ${ }^{31,32}$ Difficulties in dealing with professional or academic stress may result in burnout. ${ }^{25,33}$ Traditionally, the following three dimensions are considered in burnout: emotional exhaustion, which occurs when an individual is drained of his or her emotional resources because of having an excessive workload; depersonalization, which is the development of cynical attitudes that can create a heartless perception of others; and personal accomplishment, which is an individual's personal assessment of his or her professional competence, capability and successfulness in the work environment. ${ }^{34}$

Furthermore, health care students and professionals who deal with patients are subject to emotionally loaded interactions and therefore more prone to emotional stress and burnout. ${ }^{35}$ As a consequence, they may become less able to appreciate the patients' perspective and less empathic, and choose to protect themselves through depersonalization. ${ }^{36-38}$ Conversely, some research has shown that a health care provider's ability to consider patients' perspectives and act compassionately enhances their sense of professional accomplishment, and thereby reduces depersonalization. ${ }^{39,40}$ High burnout levels among medical, ${ }^{41}$ dental, ${ }^{42}$ pharmacy, ${ }^{43}$ and nursing students ${ }^{44}$ may be a consequence of dealing with academic stress, ${ }^{25,33}$ social and family demands, ${ }^{43}$ and exposure to emotional suffering. ${ }^{45}$ High levels of stress during school years, that lead to student burnout are related to intrinsic and contextual variables. ${ }^{46,47}$ Other researchers have reported the deleterious effects to students' psychological health that can occur as a result of poor adjustment to academic environment and curriculum, ${ }^{48}$ high expectations,${ }^{49}$ family and peer pressure, ${ }^{50}$ and economic difficulties. ${ }^{51}$

The objective of this study was to evaluate empathy, attachment style, burnout, and academic satisfaction in a group of pharmacy students. We also explored gender differences and assessed the extent to which empathy, attachment, and burnout influenced students' academic satisfaction.

\section{METHODS}

Students from the first four years of the Faculty of Pharmacy of the University of Porto (FFUP) were invited to participate in the study. All who agreed to participate were included after providing written consent. The data were collected in May 2015. Final-year students were unable to participate because of conflicts with their academic schedule.

The Faculty of Pharmacy administers a five-year integrated Master of Pharmaceutical Sciences degree program. The first and second years of the curriculum cover the physical, chemical, and biological sciences. The third and fourth years cover technological and health sciences, including pharmacognosy, toxicology, and pharmaceutical technology. The last year of the curriculum comprises practical courses, seminars, and clerkships in community and hospital pharmacy. A research project is also required in the fifth curricular year.

Training in communication skills has been incorporated into the curriculum at FFUP since 2015. Seminars with a practical component are included in the fifth year for students completing clerkships. The curricular unit addresses basic communication strategies, empathy, and how to deal with emotions and deliver difficult information. We surveyed 410 pharmacy students divided into two groups. Group 1 included 200 students who were enrolled in the first or second year of pharmacy school, and group 2 included 210 students who were enrolled in the third or fourth year of the program (Figure 1). A battery of self-assessment instruments covering sociodemographic characterization, empathy, attachment, and burnout, and an original academic satisfaction survey were administered. 


\section{American Journal of Pharmaceutical Education 2019; 83 (5) Article 6706.}

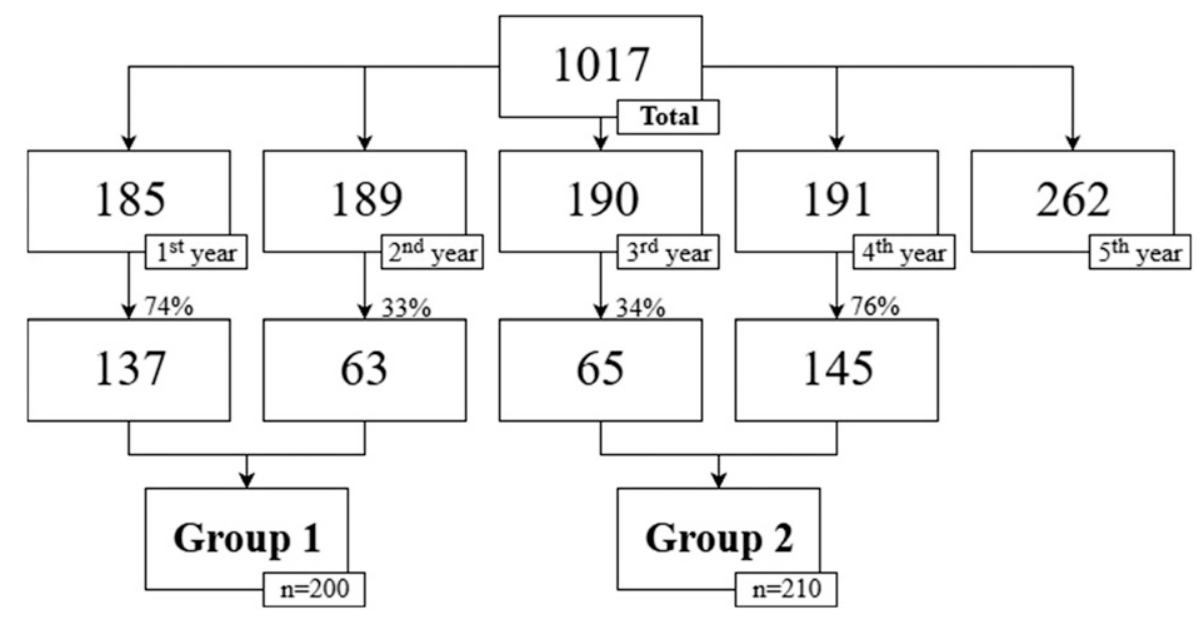

Figure 1. Total Student Population and Response Rates

The Interpersonal Reactivity Index (IRI) has been widely used to assess empathy in clinical and research settings, permitting a multidimensional approach to assessing individual differences in empathy. ${ }^{52-54}$ Studies involving residents, medical students, and physicians have used the IRI extensively to measure empathy according to the following four subscales: perspective taking (IRI-PT), empathic concern (IRI-EC), personal distress (IRI-PD), and fantasy (IRI-FS), which denotes a tendency to imaginatively transpose oneself into fictional situations (eg, books, movies, daydreams). ${ }^{24}$ The IRI offers good internal reliability. ${ }^{55}$ The Portuguese version of the instrument was used in this study. ${ }^{56}$

The Maslach Burnout Inventory (MBI) has been validated through extensive research and is widely recognized as the leading measure of burnout. ${ }^{43,57}$ The MBIStudent Survey is specifically designed to assess students' burnout and is subdivided into three subscales: emotional exhaustion, depersonalization, and personal accomplishment. ${ }^{58}$ The instrument was validated for university students in Spain, Portugal, and the Netherlands. ${ }^{59}$ Moreover, it presents accurate psychometric properties, ${ }^{60}$ and it is considered an efficient and reliable tool to assess burnout levels among pharmacy professionals. ${ }^{61}$

The Adult Attachment Scale (AAS) is characterized by high internal consistency. In terms of its dimensions, analysis of the scale's construct validity has yielded Cronbach alpha coefficients of 0.69 for close (AAS-CL), 0.75 for depend (AAS-DE), and 0.72 for anxiety (AAS-ANX). Moreover, the scale exhibits good test-retest reliability. ${ }^{62}$ It measures adult secure, anxious, and avoidant attachment styles defined by balanced scores on the close, anxiety, and depend subscales. For this study, we used the Portuguese version of the AAS. ${ }^{63}$

This original scale for academic satisfaction was developed for a study involving medical students by re- searchers who sought to measure students' satisfaction with relevant aspects of their academic life. The scale's development was based on a review of other validated scales. ${ }^{64-66}$ This nine-item scale assesses satisfaction with theoretical and practical curricular contents, research activity, academic life, extracurricular experiences, interpersonal relationships, and life in general. Higher scores represent higher levels of academic satisfaction, with a maximum score of 36 . In the present sample, the scale showed good internal consistency, with a Cronbach alpha of 0.74 .

This study was approved by the Faculty of Medicine of the University of Porto and the São João EPE Ethics Committee, and was conducted according to the Declaration of Helsinki. Participants received written information about the study procedures and aims and signed an informed consent form. Participants' confidentiality and anonymity were ensured through codification of the collected data.

Statistical analyses were performed using IBM SPSS Statistics, version 22.0 (IBM, Armonk, NY) for Windows. Descriptive statistics were calculated for all variables, and Pearson correlation analysis was used to identify significant correlations between variables. A multiple linear regression analysis was carried out: to assess the extent to which empathy and attachment styles influenced students' burnout; and to evaluate how attachment styles and burnout influence students' academic satisfaction using burnout and attachment styles as dependent variables to a composite endpoint.

\section{RESULTS}

The study sample comprised 410 pharmacy students with a mean age of 21 years $(\mathrm{SD}=2.6$; range $18-49$ years). The majority $(n=342,83 \%)$ of students were female. Group 1 included 200 students with a mean age of 19.6 


\section{American Journal of Pharmaceutical Education 2019; 83 (5) Article 6706.}

years $(\mathrm{SD}=2.1)$. The majority (168) of students in group 1 were female. Group 2 included 210 students with a mean age of 22.1 years (SD 2.5). The majority (174) of students in group 2 were female. The mean age of students in group 2, who were enrolled in the third and fourth years of the curriculum, was significantly greater than the mean age of students in group 1 . No significant differences were found between the two groups in gender (percentage of male and female students in each group) or marital status (percentage of students in each group who were married) (Table 1). Residence and having moved from home and family were similar in both groups (data not shown).

Comparisons between the two groups showed similar scores in all IRI subscales. Analyzing gender differences in each group, significantly higher empathic concern scores were found in female students than in male students in group 1 and group $2(p=.001$ and $p=.021$, respectively). Significantly higher scores on the fantasy subscale were also found in female students in group $1(p=.001)$. Considering the total sample, significantly higher scores for the empathic concern, personal distress, and fantasy subscales were found in female students $(p<.001, p=.006$, and $p=.001$, respectively).

Regarding the evaluation for burnout, only scores on depersonalization were different between the groups, with higher scores found among students in group 2 $(p=.006)$. When comparing burnout scores between genders, significantly higher scores for Emotional Exhaustion were found in female students both in the total sample and in group 1 ( $p=.017$ and $p=.001$, respectively). The empathy and burnout evaluations are presented in Table 2.

Students were generally satisfied with the relevant aspects of their academic life as reflected by a mean score of $25.1(\mathrm{SD}=4.9)$ out of a maximum score of 36 . Higher levels of academic satisfaction were detected in first- and second-year students than in third- and fourth-year stu- dents $(p=.003)$. No gender differences were detected in scores for this variable.

The groups had similar scores on the attachment adult scale. No significant differences in scores between male and female students were detected by the AAS. Significantly higher attachment-close and lower attachmentanxiety scores were found in pharmacy students from urban permanent home residence $(p=.001$ and $p=.008$, respectively) (data not shown). Permanent rural or urban home residence was included in the sociodemographic characterization of the students.

In the total sample, empathic perspective taking IRI-PT scores, demonstrated a significantly positive correlation with personal accomplishment scores, attachment-close scores, and attachment-depend scores $(r=.110, p=.028 ; \quad r=.141, p=.004$ and $r=.113$, $p=.024$, respectively) and a significant negative correlation with attachment-anxiety scores $(r=-.099$; $p=.048)$.

Empathic concern scores, demonstrated a significantly positive correlation with emotional exhaustion scores, attachment-close scores, and attachment-depend scores $(r=.130, p=.009 ; r=.203, p<.01$ and $r=.156$, $p=.002$, respectively). Personal distress scores showed a significantly positive correlation with burnout emotional exhaustion scores, depersonalization scores, and attachment-anxiety scores $(r=.268, p<.01 ; r=.177$, $p=.000$ and $r=.425, p=.000$, respectively) and a significantly negative correlation with personal accomplishment and attachment-close scores $(r=-.213, p=.000$ and $r=-.146, p=.003$, respectively). Fantasy style scores presented a significantly positive correlation with emotional exhaustion scores, depersonalization scores, and attachment-anxiety scores $(r=.133, p=.007 ; r=.141$, $p=.005$ and $r=.264, p<.01$, respectively).

Burnout scores showed a significant positive correlation with attachment-anxiety scores $(r=.325, p<.01)$ and a significant negative correlation with attachmentdepend and academic satisfaction scores $(r=-.135$,

Table 1. Characterization of Total Sample - Gender, Age and Marital Status

\begin{tabular}{|c|c|c|c|c|}
\hline & $\begin{array}{c}\text { Total } \\
\mathbf{n}=\mathbf{4 1 0}\end{array}$ & $\begin{array}{c}\text { Group } 1 \\
\mathbf{n}=\mathbf{2 0 0}\end{array}$ & $\begin{array}{c}\text { Group } 2 \\
n=210\end{array}$ & $p$ value \\
\hline Gender n (\%) & & & & .670 \\
\hline Male & $67(16)$ & $31(16)$ & $36(17)$ & \\
\hline Female & $342(83)$ & $168(84)$ & $174(83)$ & \\
\hline Missing & 1 & 1 & 0 & \\
\hline Age years M (SD) & $20.9(3)$ & $19.6(2)$ & $22.1(3)$ & $<.001$ \\
\hline Marital status n (\%) & & & & .972 \\
\hline Single & $408(99)$ & 199 (99) & 209 (99) & \\
\hline Married & $2(1)$ & $1(1)$ & $1(1)$ & \\
\hline
\end{tabular}


American Journal of Pharmaceutical Education 2019; 83 (5) Article 6706.

Table 2. Interpersonal Reactivity Index and Maslach Burnout Inventory Scores for Pharmacy Students

\begin{tabular}{|c|c|c|c|c|c|}
\hline & \multicolumn{2}{|c|}{ Total } & \multirow[b]{2}{*}{$\begin{array}{c}\text { Group } 1 \\
\mathbf{n}=\mathbf{2 0 0}\end{array}$} & \multirow[b]{2}{*}{$\underset{n=210}{\text { Group } 2}$} & \multirow[b]{2}{*}{$p$ Value } \\
\hline & $\begin{array}{l}\text { Male } \\
\mathrm{n}=67\end{array}$ & $\begin{array}{c}\text { Female } \\
n=342\end{array}$ & & & \\
\hline IRI-PT M (SD) & $15.9(3.7)$ & $16.0(4.0)$ & $15.9(3.8)$ & $16.1(4.1)$ & $.609^{3}$ \\
\hline range & 6-24 & 3-24 & 3-24 & $5-24$ & \\
\hline IRI-EC & $\begin{array}{c}15.9(4.5)^{* *} \\
7-24\end{array}$ & $\begin{array}{c}18.1(4.0) \\
0-24\end{array}$ & $\begin{array}{c}17.6(4.0) \\
0-24\end{array}$ & $\begin{array}{c}17.9(4.3) \\
1-24\end{array}$ & .523 \\
\hline IRI-PD & $\begin{array}{c}10.2(3.9)^{* *} \\
1-20\end{array}$ & $\begin{array}{c}11.9(4.7) \\
0-23\end{array}$ & $\begin{array}{c}11.8(4.5) \\
0-23\end{array}$ & $\begin{array}{c}11.4(4.7) \\
0-23\end{array}$ & .333 \\
\hline IRI-FS & $\begin{array}{c}12.4(5.7)^{* *} \\
0-24\end{array}$ & $\begin{array}{c}14.8(5.5) \\
0-24\end{array}$ & $\begin{array}{c}14.2(5.6) \\
0-24\end{array}$ & $\begin{array}{c}14.6(5.6) \\
0-24\end{array}$ & .501 \\
\hline MBI-EE & $\begin{array}{c}17.6(5.9)^{*} \\
1-29^{2}\end{array}$ & $\begin{array}{c}19.5(6.0) \\
3-30\end{array}$ & $\begin{array}{c}18.8(6.1) \\
1-30\end{array}$ & $\begin{array}{c}19.5(5.9) \\
5-30\end{array}$ & .238 \\
\hline MBI-DE & $\begin{array}{c}9.1(5.9) \\
0-24\end{array}$ & $\begin{array}{c}8.7(5.9) \\
0-24\end{array}$ & $\begin{array}{c}7.9(5.6) \\
0-24\end{array}$ & $\begin{array}{c}9.5(6.0) \\
0-24\end{array}$ & $.006^{* *}$ \\
\hline MBI-PA & $\begin{array}{c}22.1(5.9) \\
7-34\end{array}$ & $\begin{array}{c}21.7(5.6) \\
5-36\end{array}$ & $\begin{array}{c}21.4(5.5) \\
7-36\end{array}$ & $\begin{array}{c}22.1(5.7) \\
5-35\end{array}$ & .178 \\
\hline
\end{tabular}

$t$-test was used to determine significance, defined as $* p<.05$ and $* *$ as $p<.01$

IRI-PT = Interpersonal Reactivity Index-Perspective Taking; IRI-EC=Interpersonal Reactivity Index-Empathic Concern; IRI-PD=Interpersonal Reactivity Index-Personal Distress; IRI-FS=Interpersonal Reactivity Index-Fantasy Scale;

MBI-EE =Emotional Exhaustion; MBI-DE=Depersonalization; MBI-PA=Personal Accomplishment

$* p<.05 ; * * p<.01$

$p=.007$ and $r=-.266, p<.01$, respectively). Depersonalization scores showed a significant positive correlation with attachment-anxiety scores $(r=.335, p=.000)$ and a significant negative correlation with attachmentclose scores, attachment-depend scores, and academic satisfaction scores $(r=-.190, \quad p=.000 ; \quad r=-.166$, $p=.001$ and $r=-.584, p<.01$, respectively). Personal accomplishment scores showed a significant positive correlation with attachment-close style scores and academic satisfaction scores $(r=.142, p=.004$ and $r=.343, p<.01$, respectively) and a significant negative correlation with attachment-anxiety scores $(r=-.223, p<.01)$.

Attachment-close scores demonstrated a significant positive correlation with academic satisfaction scores $(r=.190, p=.000)$. Similarly, attachment-depend scores showed a significant positive correlation with academic satisfaction scores $(r=.243, p=.000)$. Lastly, as expected, attachment-anxiety scores presented a significant negative correlation with academic satisfaction $(r=-.291$, $p=.000)$. Correlations between variables are shown in Table 3 .

The strong, multiple correlations detected between variables (Table 3 ) were further evaluated using a multiple linear regression analysis with burnout and academic satisfaction as dependent variables (Table 4). A dependent attachment relationship style was associated with a positive prediction of academic satisfaction, while anx- ious attachment was associated with a significant negative prediction of academic satisfaction.

When the components emotional exhaustion, depersonalization, and personal accomplishment were added, $39 \%$ of students' academic satisfaction was explained. In that circumstance, dependent attachment and personal accomplishment were significant positive predictors and depersonalization was a significant negative predictor of students' academic satisfaction. Gender and attachment styles explained $11 \%$ of students' empathic concern; they were significant positive predictors of students' empathy, as detailed in Table 4.

\section{DISCUSSION}

This study reports a noteworthy capacity of pharmacy students to understand patients' perspective and comprehend their feelings. Moreover, in accordance with previous research, ${ }^{67}$ female participants were found to possess higher empathic ability. Whether at the beginning of or in the latter stages of their pharmacy degree program, students reported a similar ability to convey emotional support and understanding to others, which has been shown to be a determining factor in the therapeutic effects and health outcomes they will achieve when caring for their future patients. A decline in empathy among health care students as they progress through the curriculum is frequently assumed, ${ }^{68,69}$ although others have stated that these reports of erosion of empathy have been inflated. ${ }^{70}$ 


\section{American Journal of Pharmaceutical Education 2019; 83 (5) Article 6706.}

Table 3. Pearson's Correlations Total Sample

\begin{tabular}{lccccccccccc}
\hline & $\begin{array}{c}\text { IRI- } \\
\text { PT }\end{array}$ & $\begin{array}{c}\text { IRI- } \\
\text { EC }\end{array}$ & $\begin{array}{c}\text { IRI- } \\
\text { PD }\end{array}$ & $\begin{array}{c}\text { IRI- } \\
\text { FS }\end{array}$ & $\begin{array}{c}\text { MBI- } \\
\text { EE }\end{array}$ & $\begin{array}{c}\text { MBI- } \\
\text { DE }\end{array}$ & $\begin{array}{c}\text { MBI- } \\
\text { PA }\end{array}$ & $\begin{array}{c}\text { AAS- } \\
\text { CL }\end{array}$ & $\begin{array}{c}\text { AAS- } \\
\text { DE }\end{array}$ & $\begin{array}{c}\text { AAS- } \\
\text { ANX }\end{array}$ & $\begin{array}{c}\text { Academic } \\
\text { Satisfaction }\end{array}$ \\
\hline IRI-EC & $.332^{* *}$ & 1.0 & & & & & & & & & \\
IRI-PD & $-.172^{* *}$ & $.206^{* *}$ & 1.0 & & & & & & & & \\
IRI-FS & $.166^{* *}$ & $.389^{* *}$ & $.248^{* *}$ & 1.0 & & & & & & & \\
MBI-EE & -.053 & $.130^{* *}$ & $.268^{* *}$ & $.133^{* *}$ & 1.0 & & & & & & \\
MBI-DE & -.090 & -.066 & $.177^{* *}$ & $.141^{* *}$ & $.430^{* *}$ & 1.0 & & & & & \\
MBI-PA & $.110^{*}$ & .078 & $-.213^{* *}$ & -.051 & $-.135^{* *}$ & $-.368^{* *}$ & 1.0 & & & & \\
AAS-CL & $.141^{* *}$ & $.203^{* *}$ & $-.146^{* *}$ & .015 & -.080 & $-.190^{* *}$ & $.142^{* *}$ & 1.0 & & & \\
AAS-DE & $.113^{*}$ & $.156^{* *}$ & -.059 & .014 & $-.135^{* *}$ & $-.166^{* *}$ & .034 & $.419^{* *}$ & 1.0 & & \\
AAS-ANX & $-.099^{*}$ & .085 & $.425^{* *}$ & $.264^{* *}$ & $.325^{* *}$ & $.335^{* *}$ & $-.223^{* *}$ & $-.312^{* *}$ & $-.333^{* *}$ & 1.0 & \\
Academic & .069 & .033 & -.092 & -.027 & $-.266^{* *}$ & $-.584^{* *}$ & $.343^{* *}$ & $.190^{* *}$ & $.243^{* *}$ & $-.291^{* *}$ & 1.0 \\
$\quad$ Satisfaction & & & & & & & & & & &
\end{tabular}

Pearson's Correlations test was used to determine significance, defined as $* p<.05$ and $* *$ as $p<.01$

IRI-PT = Interpersonal Reactivity Index-Perspective Taking; IRI-EC=Interpersonal Reactivity Index-Empathic Concern; IRI-PD=Interpersonal Reactivity Index-Personal Distress; IRI-FS=Interpersonal Reactivity Index-Fantasy Scale;

MBI-EE $=$ Emotional Exhaustion; MBI-DE $=$ Depersonalization; MBI-PA=Personal Accomplishment

AAS-CL $=$ Attachment Adult Scale Close; AAS-DE $=$ Attachment Adult Scale Depend; AAS-ANX = Attachment Adult Scale Anxiety

Interestingly, some studies involving Portuguese medical students have detected higher empathy scores in students in latter curricular years, ${ }^{71,72}$ and shown that patient-care activities and continuous socioemotional stimulation can increase students' empathic ability. ${ }^{69,73-75}$

In our study, we identified significant associations between pharmacy students' attachment styles and their ability to express empathy. Attachment theory has previously been used to explain differences found in students' and professionals' abilities to appropriately deal with and support emotional distress in patients. . $^{17,76,77}$ Students presenting a more close or secure attachment were more prone to consider others' perspectives and to empathically care for others. These results are in line with the finding of a higher ability to detect and respond to emotions among clinicians with more secure attachment styles. ${ }^{20,21}$ Conversely, students with a tendency toward an anxious attachment style revealed higher distress in their interpersonal relationships, demonstrated lower ability to respond to patients' emotions, and were less able to "put themselves in others' shoes."

The results from the burnout evaluation showed that female students had higher scores of emotional exhaustion and depersonalization while male students had higher personal accomplishment scores, which was consistent with findings from previous reports. ${ }^{43}$ Women are more susceptible to social desirability, more eager to face studying demands and apparently prepare more rigorously for examinations, all of which result in higher stress levels. ${ }^{71}$ Burnout and its potentially negative effects during pharmacy undergraduate studies have been increasingly reported in the literature. ${ }^{43,71,72}$ Similarly, we detected higher scores of depersonalization among students in their last year of the pharmacy program. Frequently assessing pharmacy students for burnout and implementing appropriate interventions and preventive strategies could circumvent or mitigate students' psychological distress and emotional exhaustion, thereby enhancing their ability to cope with academic and future clinical challenges. ${ }^{35}$

In our study, the characteristics consistently predicting students' burnout were enrollment in the last two years of the curriculum and having an anxious attachment style. A lower ability to deal with academic stress, therefore, appears to be related to students' interpersonal relational style and the challenges students face in the last years of pharmacy school.

Among our participants, student burnout eroded academic satisfaction. Students reporting lower levels of academic satisfaction also had higher levels of burnout, supporting the hypothesis that students' depersonalization may be a possible explanation for lower academic satisfaction. ${ }^{78}$ Low academic satisfaction can undermine students' satisfaction and accomplishments in their future professional lives. ${ }^{79,80}$ Psychological interventions that were previously used to manage students' psychological distress and lack of academic motivation ${ }^{41,81,82}$ could be used to reduce burnout symptoms among pharmacy students and might have beneficial results in our population.

These results also underscore the value of monitoring students' characteristics to prevent academic stress and burnout. Students with secure attachment had higher satisfaction with relevant aspects of their academic life, 


\section{American Journal of Pharmaceutical Education 2019; 83 (5) Article 6706.}

Table 4. Linear Regressions Predicting Students' Depersonalization, Academic Satisfaction and Empathic Concern

\begin{tabular}{|c|c|c|c|}
\hline Depersonalization & B & SE & $\boldsymbol{\beta}$ \\
\hline \multicolumn{4}{|l|}{ Step 1} \\
\hline AAS-CL & -.143 & .097 & -.079 \\
\hline AAS-DE & -.057 & .088 & -.035 \\
\hline AAS-ANX & .346 & .057 & $.313 * * *$ \\
\hline $\mathrm{R}^{2}=.13(.12)^{1}$ & & & $\mathrm{~F}(3,382)=18.979 * * 2$ \\
\hline \multicolumn{4}{|l|}{ Step 2} \\
\hline AAS-CL & -.112 & .098 & -.062 \\
\hline AAS-DE & -.038 & .088 & -.024 \\
\hline AAS-ANX & .360 & .058 & $.326 * * *$ \\
\hline IRI-PT & -.037 & .076 & -.025 \\
\hline IRI-EC & -.102 & .074 & -.072 \\
\hline $\mathrm{R}^{2}=.14(.13)$ & & & $\mathrm{F}(5,380)=11.988^{* *}$ \\
\hline Academic Satisfaction & B & SE & $\boldsymbol{\beta}$ \\
\hline \multicolumn{4}{|l|}{ Step 1} \\
\hline AAS-CL & .058 & .078 & .041 \\
\hline AAS-DE & .206 & .070 & $.162 * *$ \\
\hline AAS-ANX & -.189 & .045 & $-.222 * * *$ \\
\hline $\mathrm{R}^{2}=.11(.11)$ & & & $\mathrm{F}(3,374)=15.800^{* *}$ \\
\hline \multicolumn{4}{|l|}{ Step 2} \\
\hline AAS-CL & -.034 & .065 & -.024 \\
\hline AAS-DE & .194 & .059 & $.153 * *$ \\
\hline AAS-ANX & -.027 & .040 & -.032 \\
\hline MBI-EE & .002 & .035 & .003 \\
\hline MBI-DE & -.393 & .038 & $-.504 * * *$ \\
\hline MBI-PA & .125 & .036 & $.152 * *$ \\
\hline $\mathrm{R}^{2}=.39(.38)$ & & & $\mathrm{F}(6,371)=40.104 * *$ \\
\hline Empathic Concern & B & SE & $\boldsymbol{\beta}$ \\
\hline \multicolumn{4}{|l|}{ Step 1} \\
\hline Gender & 2.165 & .562 & $.191 * * *$ \\
\hline $\mathrm{R}^{2}=.04$ & & & $\mathrm{~F}(1,251)=14.854 * *$ \\
\hline \multicolumn{4}{|l|}{ Step 2} \\
\hline Gender & 1.958 & .543 & $.173 * * *$ \\
\hline AAS-CL & .233 & .069 & $.183 * *$ \\
\hline AAS-DE & .172 & .062 & $.150 * *$ \\
\hline AS-ANX & .148 & .040 & $.190 * * *$ \\
\hline $\mathrm{R}^{2}=.11(.10)$ & & & $\mathrm{F}(4,192)=12.220 * *$ \\
\hline
\end{tabular}

$\mathrm{R}^{2}=\mathrm{R}$ Square (Adjusted R Square); $\mathrm{F}(\mathrm{df}) ; \mathrm{B}=$ unstandardized coefficient; $\mathrm{SE}=$ standard error; $\beta=$ standardized coefficient; $* * p<.01$; $* * * p<.001$

IRI-PT = Interpersonal Reactivity Index-Perspective Taking; IRI$\mathrm{EC}=$ Interpersonal Reactivity Index-Empathic Concern; IRI$\mathrm{PD}=$ Interpersonal Reactivity Index-Personal Distress; IRIFS = Interpersonal Reactivity Index-Fantasy Scale; MBI-EE =Emotional Exhaustion; MBI-DE=Depersonalization; MBI-PA $=$ Personal Accomplishment

AAS-CL $=$ Attachment Adult Scale Close; AAS-DE $=$ Attachment Adult Scale Depend; AAS-ANX = Attachment Adult Scale Anxiety

while anxiously attached students had lower satisfaction scores, emphasizing the importance of early psychological evaluation to identify personal characteristics that may influence students' academic fulfillment and help them become more resilient to stressful experiences. Moreover, a student's ability to seek support from others and have successful interpersonal relationships may contribute to the student having a more positive view of his or her academic life.

This study had several limitations. The cross-sectional design used was unable to identify causal relationships. Engaging in a deeper exploration of causes for academic stress could have added strength to the results and conclusions. In addition, self-reported empathy represents a limited evaluation of empathic ability compared with evaluation by an external observer. Furthermore, self-evaluation may introduce social desirability bias. Finally, although the sample size was adequate, the generalizability of the results is limited because the study was conducted at a single institution.

\section{CONCLUSION}

Pharmacy students in our study simultaneously indicated feeling considerable academic satisfaction and personal distress, which demonstrated their ability to maintain a positive appraisal of their academic life despite the challenges they were experiencing. Nevertheless, the tendency for students enrolled in their last two years of pharmacy school to have higher levels of professional stress and lower fulfillment signals a need for the school to monitor these students' for emotional exhaustion and an inability to cope with the academic challenges that they face during and beyond pharmacy school.

Regardless of the academic year in which they were enrolled, pharmacy students' responses indicated they possessed a noteworthy ability to empathize with others. However, those students who were having more difficulty with close relationships demonstrated higher levels of burnout, lower ability to respond to patients' emotions, and lower academic satisfaction. We suggest monitoring those intrinsic characteristics in students that can undermine professionalism, performance, and resistance to stressful experiences. Conversely, preventive and therapeutic strategies can work powerfully to minimize distress and prepare pharmacy students to handle academic and professional challenges.

\section{ACKNOWLEDGMENTS}

The authors acknowledge the students and the teaching staff of the FFUP, Professor Manuela Mourato, and particularly the Faculty Director, Professor Sousa Lobo, for their valuable contribution to motivate students' participation and coordinating the data collection. We are 


\section{American Journal of Pharmaceutical Education 2019; 83 (5) Article 6706.}

thankful to Raquel and David Tamegão Rothwell for English language editing of the manuscript.

\section{REFERENCES}

1. Halpern J. From idealized clinical empathy to empathic communication in medical care. Med Health Care Philos. 2014;17(2):301-311.

2. Shah B, Chewning B. Conceptualizing and measuring pharmacistpatient communication: a review of published studies. Res Social Adm Pharm. 2006;2(2):153-185.

3. Morse JM, Anderson G, Bottorff JL, et al. Exploring empathy: a conceptual fit for nursing practice? Image J Nurs Sch. 1992;24(4):273-280.

4. Florentine R, Hillhouse MP. Drug treatment effectiveness and client-counselor empathy: exploring the effects of gender and ethnic congruency. Journal of Drug Issues. 1999;29(1):59-74.

5. Derksen F, Bensing J, Lagro-Janssen A. Effectiveness of empathy in general practice: a systematic review. Br J Gen Pract. 2013;63(606):e76-84.

6. WHO. The role of the pharmacist in the health care system, preparing the future pharmacist: curricular development. 1997.

7. McDonough RP, Bennett MS. Improving communication skills of pharmacy students through effective precepting. Am J Pharm Educ. 2006;70(3):Article 58.

8. Kerr JL, Stahnke AM, Behnen EM. Assessing empathy and selfefficacy levels of pharmacy students in an elective diabetes management course. Am J Pharm Educ. 2015;79(3):Article 42. 9. Skoy ET, Eukel HN, Frenzel JE, Werremeyer A, McDaniel B. Use of an auditory hallucination simulation to increase student pharmacist empathy for patients with mental illness. Am J Pharm Educ. 2016;80(8):Article 142. 10. Curley LE, McDonald M, Aspden T. Use of a fictitious community-based virtual teaching platform to aid in the teaching of pharmacy practice skills: Student perspectives after initial implementation. J Pharm Policy Pract. 2016;9:24.

11. Jeon S, Cho E. Assessment of Korean pharmacy students' empathy using the Jefferson scale of empathy. Am J Pharm Educ. 2015;79(5):Article 67.

12. Osterberg L, Blaschke T. Adherence to medication. $N$ Engl J Med. 2005;353(5):487-497.

13. Anderson EB. Patient-centeredness: a new approach. Nephrology News \& Issues. 2002;16(12):80-82.

14. Zolnierek KB, Dimatteo MR. Physician communication and patient adherence to treatment: a meta-analysis. Medical Care. 2009;47(8):826-834.

15. Ngoh LN. Health literacy: a barrier to pharmacist-patient communication and medication adherence. J Am Pharm Assoc. 2009;49(5):e132-146; quiz e147-139.

16. Mercer SW, Higgins M, Bikker AM, et al. General practitioners' empathy and health outcomes: a prospective observational study of consultations in areas of high and low deprivation. Ann Fam Med.

2016;14(2):117-124.

17. Wei M, Liao KY, Ku TY, Shaffer PA. Attachment, selfcompassion, empathy, and subjective well-being among college students and community adults. J Pers. 2011;79(1):191-221.

18. Wayment HA. Attachment style, empathy, and helping following a collective loss: evidence from the September 11 terrorist attacks. Attach Hum Dev. 2006;8(1):1-9.

19. Bowlby J. Attachment and Loss. New York: Basic Books; 1969. 20. Dozier M, Cue KL, Barnett L. Clinicians as caregivers: role of attachment organization in treatment. J Consult Clin Psychol. 1994;62(4):793-800.
21. Tan A, Zimmermann C, Rodin G. Interpersonal processes in palliative care: an attachment perspective on the patient-clinician relationship. Palliat Med. 2005;19(2):143-150.

22. Georgi E, Petermann F, Schipper M. Are empathic abilities learnable? Implications for social neuroscientific research from psychometric assessments. Social Neuroscience. 2014;9(1):74-81. 23. Esquerda M, Yuguero O, Viñas J, Pifarré J. La empatía médica, ¿nace o se hace? Evolución de la empatía en estudiantes de medicina. Atención Primaria. 2016;48(1):8-14.

24. Davis MH. Measuring individual-differences in empathy - evidence for a multidimensional approach. J Pers Soc Psychol. 1983;44(1):113-126. 25. Iacovides A, Fountoulakis KN, Kaprinis S, Kaprinis G. The relationship between job stress, burnout and clinical depression. $J$ Affec Disor. 2003;75(3):209-221.

26. Sperling MB, Berman WH. Attachment in Adults: Clinical and Developmental Perspectives. Guilford Press; 1994.

27. Sanford K. Two dimensions of adult attachment: Further validation. J Soc Pers Relat. 1997;14(1):133-143.

28. Ciechanowski PS, Russo JE, Katon WJ, Walker EA.

Attachment theory in health care: the influence of relationship style on medical students' specialty choice. Medical Education.

2004;38(3):262-270.

29. Cherry MG, Fletcher I, O'Sullivan H. The influence of medical students' and doctors' attachment style and emotional intelligence on their patient-provider communication. Patient Educ Couns.

2013;93(2):177-187.

30. Daniel SI. Adult attachment patterns and individual psychotherapy: a review. Clin Psychol Rev. 2006;26(8):968-984.

31. Bakker AB, Costa PL. Chronic job burnout and daily functioning: A theoretical analysis. Burnout Research.

2014;1(3):112-119.

32. Finney C, Stergiopoulos E, Hensel J, Bonato S, Dewa CS. Organizational stressors associated with job stress and burnout in correctional officers: a systematic review. BMC Public Health. 2013;13:82-82.

33. Jacobs SR, Dodd DK. Student burnout as a function of personality, social support, and workload. J Coll Stud Dev. 2003;44(3):291-303.

34. Schaufeli WB, Bakker AB, van der Heijden FMMA, Prins JT. Workaholism, burnout and well-being among junior doctors: The mediating role of role conflict. Work Stress. 2009;23(2):155-172. 35. Higuchi $Y$, Inagaki $M$, Koyama $T$, et al. A cross-sectional study of psychological distress, burnout, and the associated risk factors in hospital pharmacists in Japan. BMC Public Health. 2016;16:534.

36. Zenasni F, Boujut E, Woerner A, Sultan S. Burnout and empathy in primary care: three hypotheses. Br J Gen Pract. 2012;62(600):346-347. 37. Thomas MR, Dyrbye LN, Huntington JL, et al. How do distress and well-being relate to medical student empathy? A multicenter study. J Gen Inter Med. 2007;22(2):177-183.

38. Brazeau CM, Schroeder R, Rovi S, Boyd L. Relationships between medical student burnout, empathy, and professionalism climate. Acad Med. 2010;85(10 Suppl):S33-36.

39. Hojat M, Mangione S, Nasca TJ, et al. An empirical study of decline in empathy in medical school. Medical Education. 2004;38(9):934-941.

40. Krasner MS, Epstein RM, Beckman H, et al. Association of an educational program in mindful communication with burnout, empathy, and attitudes among primary care physicians. JAMA. 2009;302(12):1284-1293. 


\section{American Journal of Pharmaceutical Education 2019; 83 (5) Article 6706.}

41. Ried LD, Motycka C, Mobley C, Meldrum M. Comparing selfreported burnout of pharmacy students on the founding campus with those at distance campuses. Am J Pharm Educ. 2006;70(5):Article 114. 42. Gibbons C. Stress, coping and burn-out in nursing students. Int J Nurs Stud. 2010;47(10):1299-1309.

43. Galan F, Rios-Santos JV, Polo J, Rios-Carrasco B, Bullon P. Burnout, depression and suicidal ideation in dental students. Med Oral Patol Oral. 2014;19(3):E206-E211.

44. Fares J, Saadeddin Z, Al Tabosh H, et al. Extracurricular activities associated with stress and burnout in preclinical medical students. J Epidemiol Glob Health. 2015.

45. Zapf D. Emotion work and psychological well-being: a review of the literature and some conceptual considerations. Human Resource Management Review. 2002;12(2):237-268.

46. Stallman HM. Psychological distress in university students: a comparison with general population data. Australian Psychologist. 2010;45(4):249-257.

47. Salzer MS. A comparative study of campus experiences of college students with mental illnesses versus a general college sample. J Am Coll Health. 2012;60(1):1-7.

48. Omokhodion FO, Gureje O. Psychosocial problems of clinical students in the University of Ibadan Medical School. Afr J Med Med Sci. 2003;32(1):55-58.

49. Aghamolaei T, Shirazi M, Dadgaran I, Shahsavari H, Ghanbarnejad A. Health students' expectations of the ideal educational environment: a qualitative research. J Adv Med Educ Prof. 2014;2(4):151-157.

50. Mandal A, Ghosh A, Sengupta G, Bera T, Das N, Mukherjee S. Factors affecting the performance of undergraduate medical students: a perspective. Indian J Community Med. 2012;37(2):126-129.

51. Hysenbegasi A, Hass SL, Rowland CR. The impact of depression on the academic productivity of university students. J Ment Health Policy Econ. 2005;8(3):145-151.

52. Quince T, Thiemann P, Benson J, Hyde S. Undergraduate medical students' empathy: current perspectives. Adv Med Educ Pract. 2016;7:443-455.

53. Quince TA, Kinnersley P, Hales J, et al. Empathy among undergraduate medical students: a multi-centre cross-sectional comparison of students beginning and approaching the end of their course. BMC Med Educ. 2016;16:92.

54. Costa P, de Carvalho-Filho MA, Schweller M, et al. Measuring medical students' empathy: exploring the underlying constructs of and associations between two widely used self-report instruments in five countries. Acad Med. 2016.

55. Davis. A multidimensional approach to individual differences in empathy. 1980.

56. Limpo T, Alves Ra, Catro SL. Medir a empatia: adaptação portuguesa do índice de reactividade interpessoal. Laboratório de Psicologia. 2010;8(2):171-184.

57. Al-Dubai SA, Ganasegeran K, Perianayagam W, Rampal KG. Emotional burnout, perceived sources of job stress, professional fulfillment, and engagement among medical residents in Malaysia. Scientific World Journal. 2013;2013:137620.

58. Schaufeli WB, Martinez IM, Pinto AM, Salanova M, Bakker AB. Burnout and engagement in university students - A cross-national study. J Cross Cult Psychol. 2002;33(5):464-481.

59. Maslach C, S.E, Jackson \& Leiter, M. P. Maslach Burnout Inventory. Consulting Psycologist Press. 1996.

60. Schwab RL, Iwanicki EF. Perceived role conflict, role ambiguity, and teacher burnout. Educational Administration Quarterly. 1982;18(1):60-74.
61. Calgan Z, Aslan D, Yegenoglu S. Community pharmacists' burnout levels and related factors: an example from Turkey. Int J Clin Pharm. 2011;33(1):92-100.

62. Collins NL, Read SJ. Adult attachment, working models, and relationship quality in dating couples. J Pers Social Psychol. 1990;58(4):644-663.

63. Canavarro MC. Relações afectivas ao Longo do ciclo de vida e saúde mental. 1995.

64. Ramos AM, Barlem JGT, Lunardi VL, Barlem ELD, Silveira RSd, Bordignon SS. Satisfaction with academic experience among undergraduate nursing students. Texto \& Contexto - Enfermagem. 2015;24:187-195.

65. Wach FS, Karbach J, Ruffing S, Brünken R, Spinath FM. University students' satisfaction with their academic studies: personality and motivation matter. Front Psychol. 2016;7:55. 66. Huebner ES. Initial development of the student's life satisfaction scale. Sch Psychol Int. 1991;12(3):231-240.

67. Tamayo CA, Rizkalla MN, Henderson KK. Cognitive, behavioral and emotional empathy in pharmacy students: targeting programs for curriculum modification. Front Pharmacol. 2016;7:96. 68. Nunes P, Williams S, Sa B, Stevenson K. A study of empathy decline in students from five health disciplines during their first year of training. Int J Med Educ. 2011;2:12-17.

69. Hojat M, Vergare MJ, Maxwell K, et al. The devil is in the third year: a longitudinal study of erosion of empathy in medical school. Acad Med. 2009;84(9):1182-1191.

70. Colliver JA, Conlee MJ, Verhulst SJ, Dorsey JK. Reports of the decline of empathy during medical education are greatly exaggerated: a reexamination of the research. Acad Med. 2010;85(4):588-593. 71. Taveira-Gomes I, Mota-Cardoso R, Figueiredo-Braga M. Communication skills in medical students: an exploratory study before and after clerkships. Porto Biomedical Journal. 2016.

72. Alexandra M. Reconsidering declines of empathy during medical education: a scoping review. 2015.

73. Hojat M, Axelrod D, Spandorfer J, Mangione S. Enhancing and sustaining empathy in medical students. Medical Teacher.

2013;35(12):996-1001.

74. Batt-Rawden SA, Chisolm MS, Anton B, Flickinger TE.

Teaching empathy to medical students: an updated, systematic review. Acad Med. 2013;88(8):1171-1177.

75. Hegazi I, Wilson I. Maintaining empathy in medical school: it is possible. Medical Teacher. 2013;35(12):1002-1008.

76. Mikulincer M, Florian V. Appraisal of and coping with a real-life stressful situation: the contribution of attachment styles. Personality and Social Psychology Bulletin. 1995;21(4):406-414.

77. Miller R. Intimate Relationships. McGraw-Hill Education; 2014. 78. Paro HB, Silveira PS, Perotta B, et al. Empathy among medical students: is there a relation with quality of life and burnout? PLoS One. 2014;9(4):e94133.

79. Rahmati Z. The study of academic burnout in students with high and low level of self-efficacy. Procedia - Social and Behavioral Sciences. 2015;171:49-55.

80. Sonmez GY, Capri B. The effect of stress coping program on burnout levels of high school students. 2013(July):148-165.

81. Shanafelt TD, West C, Zhao X, et al. Relationship between increased personal well-being and enhanced empathy among internal medicine residents. J Gen Intern Med. 2005;20(7):559-564.

82. Rajiah K, Saravanan C. The effectiveness of psychoeducation and systematic desensitization to reduce test anxiety among firstyear pharmacy students. Am J Pharm Educ. 2014;78(9):Article 163. 


\section{American Journal of Pharmaceutical Education 2019; 83 (5) Article 6706.}

Appendix 1. Adult Attachment Scale

\begin{tabular}{|c|c|c|c|c|c|c|c|}
\hline & \multicolumn{2}{|c|}{ TOTAL } & \multicolumn{2}{|c|}{ Group 1} & \multicolumn{2}{|c|}{ Group 2} & \multirow[b]{2}{*}{$p$} \\
\hline & $\underset{n=67}{M}$ & $\begin{array}{c}\mathrm{F} \\
\mathrm{n}=340\end{array}$ & $\begin{array}{c}M \\
n=31\end{array}$ & $\begin{array}{c}\mathbf{F} \\
\mathrm{n}=167\end{array}$ & $\underset{n=36}{M}$ & $\begin{array}{c}\text { F } \\
n=173\end{array}$ & \\
\hline AAS-CL & $\begin{array}{c}15.1(3.7)^{\mathrm{a}} \\
5-23^{\mathrm{b}}\end{array}$ & $\begin{array}{c}15.5(3.2) \\
6-24\end{array}$ & $\begin{array}{c}14.9(3.2) \\
6-20\end{array}$ & $\begin{array}{c}15.5(2.9) \\
8-23\end{array}$ & $\begin{array}{c}15.4(4.1) \\
5-23\end{array}$ & $\begin{array}{c}15.6(3.5) \\
6-24\end{array}$ & $.696^{\mathrm{c}}$ \\
\hline AAS-DE & $\begin{array}{c}12.8(4.0) \\
2-22\end{array}$ & $\begin{array}{c}12.7(3.6) \\
2-23\end{array}$ & $\begin{array}{c}12.5(4.1) \\
6-22\end{array}$ & $\begin{array}{c}13.2(3.5) \\
4-23\end{array}$ & $\begin{array}{c}13.1(4.0) \\
2-20\end{array}$ & $\begin{array}{c}12.2(3.6) \\
2-20\end{array}$ & $.139^{\mathrm{d}}$ \\
\hline AAS-ANX & $\begin{array}{c}9.8(4.8) \\
0-21\end{array}$ & $\begin{array}{c}10.5(5.5) \\
0-24\end{array}$ & $\begin{array}{c}9.8(5.1) \\
0-20\end{array}$ & $\begin{array}{c}10.5(5.3) \\
0-24\end{array}$ & $\begin{array}{c}9.9(4.6) \\
2-21\end{array}$ & $\begin{array}{c}10.5(5.7) \\
0-24\end{array}$ & $.864^{\mathrm{c}}$ \\
\hline
\end{tabular}

${ }^{\mathrm{a}}$ Mean (Standard Deviation)

${ }^{\mathrm{b}}$ Range

${ }^{\mathrm{c}} t$-test

dMann-Whitney U test

$\mathrm{n}=$ sample size $\mathrm{M}=$ Male $\mathrm{F}=$ Female; AAS-CL=Attachment Adult Scale- Close, AAS-DE=Attachment Adult Scale - Depend; AAS$\mathrm{ANX}=$ Attachment Adult Scale - Anxiety; $p<.01$ 